\title{
El desarrollo del estado de bienestar en los países capitalistas avanzados:
}

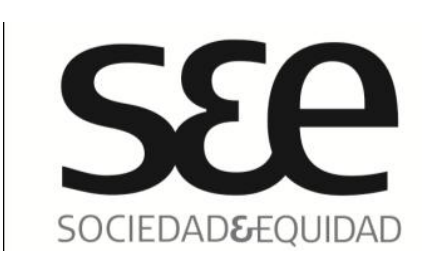

\section{Un enfoque socio-histórico}

\section{RESUMEN}

El presente artículo entrega una mirada socio-histórica sobre el Estado de Bienestar, sus orígenes, el contexto en el cual se fue desarrollando, así como su caracterización y diferencias en la sociedad europea y norteamericana desde la revisión bibliográfica de diversos autores. Se ofrece una revisión analítica de la transformación de los Estados liberales a Estados de bienestar y los avances en cuanto a derechos sociales que este cambio significó en estas sociedades. Posteriormente se analiza la caída de los Estados de bienestar y el desmantelamiento de las políticas de protección social que esto trajo consigo. Finalmente, se discute la vigencia de este modelo estatal tanto a nivel empírico como conceptual en las sociedades post-industriales.

\section{PALABRAS CLAVES}

Estado Liberal; Estado de Bienestar; Derechos Civiles, políticos y sociales; Keynesianismo; Neoliberalismo; Globalización

\section{ABSTRACT}

This article consists of a socio-historical analysis on Welfare State, its origins and the context from which it was founded, as well as its characterization and differences between European and North American societies by revising bibliography of several authors. This article offers an analytical review of the transformation from Liberal to Welfare State and the advances regarding the social rights this change meant for these societies. Next, the decline of the Welfare State and the disassemble of social protection policies that this brought will be analyzed. Finally, the permanence of the Welfare State at an empirical as well as conceptual level in postindustrial societies will be discussed.

\section{KEYWORDS}

Liberal State; Welfare Stat;, Civic, political and social rights; Keysnesianis; Neoliberalism; Globalization 


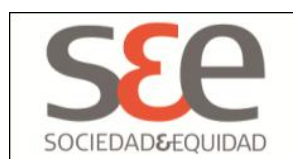

\section{Introducción}

Al analizar el desarrollo de los Estados de bienestar en las distintas sociedades, es posible dar cuenta de diversos elementos reflexivos sobre el "deber ser" de la vida social, los límites de ésta y cómo normar los derechos y garantías de las y los ciudadanos. En este afán analítico se revisan constantemente conceptos como participación ciudadana, democracia y ciudadanía social, los que explican la extensión de los derechos individuales de los ciudadanos y la creciente capacidad de manifestación de los individuos sobre las decisiones del Estado- Nación y en las nuevas formas que éste está asumiendo en la globalización.

Al centro de la discusión sobre el rol del Estado se encuentra también el surgimiento, expansión y asentamiento del capitalismo y su raíz ideológica -el liberalismo- en las sociedades industriales y post industriales. El debate sobre el lugar que debe ocupar el mercado, las facilidades o "atajos" para su autorregulación y los métodos para que los sectores más vulnerables se inserten en las economías capitalistas, se ha extendido desde el siglo XVIII hasta nuestros días, con énfasis en distintos contextos históricos como la crisis de 1929, el fin de la II Guerra Mundial, hasta la reciente quiebra de los bancos de inversión en Estados Unidos y la entrega de resguardos económicos de parte del gobierno norteamericano a la banca de su país.

A continuación se desarrollarán con mayor amplitud los temas esbozados confrontando la visión de diferentes autores frente a las transformaciones del Estado, su relación con los ciudadanos y cómo éste se hace cargo de su fin último, que es reguardar el "bien común" del colectivo social.

\section{Del Estado Liberal al Estado de Bienestar}

A lo largo del siglo XIX hasta la Segunda Guerra Mundial, los Estados occidentales van a sufrir una transformación radical, pasando de Estados liberales (del laissez-faire o "mínimo") a "Estados Sociales" o "Estados de Bienestar".

El modelo de Estado liberal parte de la premisa que el individuo se orienta racionalmente hacia la consecución de sus intereses básicos, definidos en la forma de derechos naturales: a la vida, a la libertad y a la propiedad. En "El Leviatán", escrito en 1651, Hobbes asienta las bases del liberalismo político clásico. En este texto fundacional describe a los humanos como seres en un estado natural de igualdad, pero de espíritu egoísta, hedonista y en permanente búsqueda de una posición privilegiada desde la que se puedan asegurar sus objetivos. Los conflictos de interés y las luchas por el poder definen la condición humana como una condición de guerra de todos contra todos, expresada en la célebre frase "el Hombre es el lobo del Hombre" ("Homo homini lupus") (Hobbes, 1980: 51).

Sin embargo, el autor deseaba mostrar que la preocupación por el propio interés individual no debería necesariamente llevar a conflictos interminables o a la "guerra de todos contra todos". Para establecer la forma más apropiada de pacto social, Hobbes plantea que los individuos deben renunciar a sus derechos naturales, transfiriéndolos a una autoridad poderosa que pueda forzarles a mantener sus contratos y convenios. Es entonces cuando se forman efectiva y legítimamente la esfera pública y privada, o sea el Estado y la sociedad.

En la esfera política el liberalismo levanta la problemática de cómo sostener un gobierno en un mundo marcado por la persecución legítima y razonable de los intereses individuales y qué forma debía adoptar ese gobierno para ejercer eficazmente su función. Locke y Montesquieu postularon 


\section{s\&e \\ somenowo}

la creación de límites al poder político legalmente establecido en el Estado, mediante derechos irrenunciables de los individuos, la soberanía popular y la división de poderes dentro del mismo Estado. Los sistemas políticos que se van constituyendo durante el siglo XIX seguirán estas ideas, van a ser definidos como democracias liberales y los Estados que en ese periodo emergen se configurarán en concordancia con el carácter adoptado por el sistema político.

Para producir seguridad y reducir incertidumbres, el rol del Estado liberal, según uno de sus mayores ideólogos -el economista clásico Adam Smith- se limitaba a:

Proteger a la sociedad contra la violencia e invasión de otras sociedades independientes"; (...) salvaguardar a cada miembro de la sociedad de la injusticia u opresión de cada uno de los otros miembros" en la medida de lo posible; y (...) mantener y erigir ciertos trabajos públicos y ciertas instituciones públicas. Cuándo el gobierno se limita a esas funciones básicas, una "gran sociedad" emerge. (Smith, 2000: 612)

Para poder desempeñar y financiar estas actividades y otras más, este Estado, debería tener unos ingresos permanentes, los impuestos. Al igual que Hobbes y Locke, Smith plantea que la búsqueda del beneficio personal genera beneficios sociales colectivos y el crecimiento económico sostenido es el resultado de la inteligencia del hombre. Concluye que hay que liberar la creatividad humana y esta se materializaría en la competencia y extensión del mercado. Según este enfoque el mercado permite la armonización de los intereses divergentes sin necesidad de la intervención del Estado. En ese contexto, la burguesía sintoniza perfectamente con la idea de libertad y la necesidad de buscar mercados autorregulados, propuesta por el liberalismo.

La aparición del Estado liberal significó una transformación fundamental. Como describe Polanyi:

El mercado autorregulador era algo desconocido: la aparición de la idea de autorregulación representa, sin duda alguna, una inversión radical de la tendencia que era entonces la del desarrollo. Una economía de mercado es un sistema económico regido, regulado y orientado únicamente por los mercados. La tarea de asegurar el orden en la producción y la distribución de bienes es confiada a ese mecanismo autorregulador. Lo que se espera es que los seres humanos se comporten de modo que pretendan ganar el máximo dinero posible: tal es el origen de una economía de este tipo. (Polanyi, 1989: 219).

\section{Surgimiento de la protección social}

Los Estados liberales durante el siglo XIX, en el contexto de la revolución industrial y el desarrollo de la producción capitalista, se vieron enfrentados a una serie de problemas sociales principalmente vinculados a la precarización de algunos sectores de la sociedad. La fase crítica de este sistema de mercado autorregulado, coincidió con la creación de un mercado de trabajo, en el cual los trabajadores estaban condenados a morir de hambre si no eran capaces de adaptarse a las 


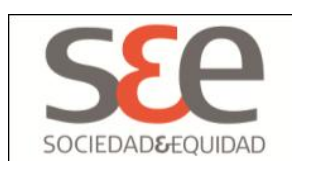

reglas del trabajo asalariado.

Desde la sociedad civil surge una respuesta asistencialista: La Iglesia se preocupa por implementar por la vía de la caridad una serie de instituciones de beneficencia que buscan ayudar a estos grupos. Sin embargo, en la Inglaterra liberal se plantea la derogación de estas instituciones por medio de una ley que plantea la abolición de toda protección social para incentivar a estos sectores a integrarse en los mercados laborales.

Este mercado desregulado, chocó tan violentamente con la sociedad, que casi de inmediato surgieron poderosas reacciones pidiendo la intervención y protección del Estado, exigiéndole, en palabras de Claus Offe, que se preocupe de "cubrir los riesgos e incertidumbres a que están expuestos los trabajadores asalariados y sus familias en la sociedad capitalista" (Offe, 1990: 75). El orden liberal comenzó a adoptar embrionarias reformas, impulsadas desde los grupos excluidos por el liberalismo, que desembocarían en la ruptura de este régimen y la constitución del Estado Bienestar. La llamada "cuestión social", que se expresó en la presión política de los movimientos obreros, impulsó a los gobiernos a cambiar las legislaciones sobre la condición social de la clase trabajadora y el trabajo. Los primeros éxitos de éstos movimientos se dieron en las fábricas, tanto en el norte de Europa, Inglaterra, como en Estados Unidos, logrando pactar nuevas condiciones de trabajo con los patronos y empresarios de la época. Surgen entonces los primeros sindicatos de clase, con el objeto de restringir la libertad de empresa y el libre juego de la fijación de los precios, y negociar mejoras en los salarios y las condiciones laborales. Sin embargo, los sindicatos no fueron los únicos actores en este proceso. Los Estados de Bienestar fueron resultado combinado de diversos factores, entre los cuáles se destaca el reformismo socialdemócrata, el socialismo cristiano, y las élites políticas y económicas conservadoras ilustradas. Todas estas fuerzas políticas y sociales en conjunto con los sindicatos impulsaron reformas de seguro obligatorio, protección al trabajo, salario mínimo, expansión de los servicios sanitarios y educativos, y alojamientos subvencionados estatalmente (Offe, 1990). También influyeron en este proceso algunas transformaciones institucionales, principalmente el surgimiento de la democracia de masas con sucesivas ampliaciones del derecho de voto hasta llegar al sufragio universal. La fase de consolidación democrática del Estado de Bienestar se completó después de la Segunda Guerra Mundial.

El cientista político Norberto Bobbio explica la aparición de actividades características del Estado de Bienestar en los diferentes países como un elemento clave de corrección del mercado autorregulado y de la mercantilización de la relación salarial:

Ahora, el mercado autorregulado y el principio de igualdad tienen exigencias incompatibles entre sí, puesto que el primero exige la no intervención del Estado y el segundo, por el contrario, postula que el Estado debe asumir la carga de eliminar todos los obstáculos que objetivamente impiden a los ciudadanos menos pudientes gozar de los derechos políticos y sociales formalmente reconocidos. La sociedad trata de defenderse del mercado autorregulado, que produce miseria, desigualdad, desocupación y alienación y, a través de la acción del Estado, trata de poner límites precisos al imperialismo de la lógica capitalista. (Bobbio, 2002: 2) 


\section{SEe \\ somenowo}

Pero el aspecto más significativo del Estado de Bienestar no se reduce a la regulación del mercado, sino que se expresa y se reconoce en el principio de la seguridad social. A través del seguro social el Estado intervino en las relaciones laborales haciéndose cargo de la precarización y la inseguridad que hasta ese momento se expresaron en el fenómeno de la cuestión social. Estos sistemas de bienestar social se fueron implantando siguiendo modelos referenciales:

- El canciller alemán Otto Von Bismarck refrendó tres leyes sociales respondiendo a las fuertes demandas de los trabajadores, la presión de las iglesias y de grupos políticos de la época. Estas leyes fueron las primeras en su tipo y consistían en un Seguro contra Enfermedad (1883); Seguro contra Accidentes de Trabajo (1884); Seguro contra la Invalidez y la Vejez (1889).

Este modelo de Estado del Bienestar se basa en un sistema de seguros sociales de carácter obligatorio que efectúa descuentos y transferencias a la renta del sujeto que está inserto en el mercado de trabajo y así contribuye con su correspondiente cuota (cotización) a su seguro social individual. La aplicación de este modelo rápidamente se extendió a Europa y luego a otras partes del mundo.

- Por otro lado, en Inglaterra el régimen de seguridad social que preconiza Beveridge, en su informe de 1942, propone la puesta en marcha de un sistema universal de seguro social solidario y coherente con 4 características principales que se aplican a todos los ciudadanos (Aracil et al, 1998: 183):

1. Un sistema generalizado, que cubra al conjunto de la población independientemente de su estatuto o de su renta.

2. Un sistema unificado y sencillo, con una sola cotización para todos los riesgos y de la misma cuantía para todos.

3. Un sistema uniforme, las prestaciones son uniformes y suficientes cualquiera que sea el nivel de renta de los interesados.

4. Un sistema centralizado, mediante un servicio público único.

La influencia de este modelo de solidaridad social en la posguerra fue enorme y se aplicó en las resoluciones de la Organización Internacional del Trabajo, OIT. Muchos países (Gran Bretaña, Bélgica, Holanda, Suiza, Suecia y Dinamarca) reformaron sus sistemas inspirándose en los principios de Beveridge. Además, la política social del Estado de Bienestar debía, mediante una financiación fiscal complementaria a las cotizaciones, conceder prestaciones familiares, mejorar la salud pública mediante la creación de un Servicio Nacional de Salud y contribuir al mantenimiento del empleo y prevención del desempleo masivo.

\section{La influencia de los conflictos internacionales y el Plan Marshall}

En este proceso de extensión de los derechos y de corrección de los efectos negativos del mercado autorregulado, adquirieron singular importancia las fases de conflictos bélicos entre Estados. Es a partir de la Segunda Guerra Mundial cuando se formula el pacto o consenso keynesiano, pacto que dará origen a los sistemas de seguridad social y de relaciones laborales 


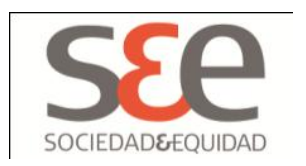

vigentes desde entonces.

El Plan Marshall, denominado oficialmente European Recovery Program o ERP, fue el principal programa de los Estados Unidos para la reconstrucción de Europa después de la Segunda Guerra Mundial. El papel protagónico del gobierno de Estados Unidos en la reconstrucción de los países europeos de la posguerra tenía como fin, por un lado, abrir lazos comerciales con Europa y, por otro, ser la contraparte política de la influencia de la URSS en el escenario internacional (Doctrina Truman).

Los recursos económicos destinados por el Plan Marshall estimularon las áreas de la producción y la economía de los Estados beneficiados. De acuerdo a Erik Hobsbawm "la gigantesca generosidad de los fondos del plan Marshall contribuyó a la modernización de todos los beneficiarios que quisieron utilizarlos con este fin - como lo hicieron Austria y Francia - y la ayuda norteamericana fue decisiva a la hora de acelerar la transformación de la Alemania Occidental y Japón" (Hobsbawm, 1998: 244).

La modernización derivada del Plan Marshall estuvo ligada a una nueva forma de organización política y manejo económico. La mayoría de los gobiernos asumen que no es posible mantener una forma de organización en los mismo términos en que se organizó la sociedad hasta antes de la guerra, que se basaban en la desregulación económica propugnada por el liberalismo.

En adelante, el Estado interviene entregando servicios y beneficios, pero otorgando además una serie de mecanismos y recursos que introducen certidumbre, seguridad y control en el manejo económico. Esta forma de intervención estatal permite superar una serie de situaciones de tensión de las fases precedentes en el Estado. Al período 1950-1970, Hobsbawm lo calificó como la "Edad de Oro" por el crecimiento económico de las sociedades industriales avanzadas de la Europa Occidental. Las políticas sociales y económicas eran el resultado de los acuerdos negociados entre el Estado, las grandes empresas capitalistas y los sindicatos para alcanzar una especie de "compromiso de clase" o "pacto social" que permitiera mantener la estabilidad y formar un Estado de Bienestar (Hobsbawm, 1998: 270).

De acuerdo a Hobsbawm esta reestructuración del capitalismo, y el avance de la internacionalización de la economía fueron fundamentales en la instauración de Estados de Bienestar en Europa. Este nuevo modelo político y económico lo definía de manera muy clara: "En lo esencial, era una especie de matrimonio entre liberalismo económico y socialdemocracia" (Hobsbawm, 1998: 273). En este periodo el Estado de Bienestar se organiza adoptando la lógica de la planificación económica. Se establecen mecanismos de regulación, se estimulan y se acepta la organización de la sociedad civil y una serie de formas de consenso y colaboración entre los principales actores productivos.

Para Jesús M. Gómez "la manifestación más clara de la consolidación del Estado del bienestar en las economías capitalistas es su propia configuración como "economías mixtas", en donde coexisten un sector privado, en el que el mercado domina como mecanismo asignador, y un sector público con una actividad intervencionista más o menos intensa" (Gómez, 1995:263). Aquí se pueden diferenciar los modelos económicos de Europa, que claramente apuestan por una presencia mayor del Estado, y las economías de Estados Unidos y Japón, con una presencia estatal mucho más débil. 


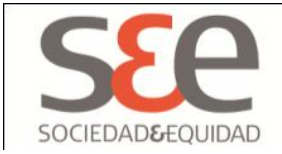

Esping-Andersen, citando a Therbon, plantea que para identificar a un verdadero Estado de Bienestar se debe partir de un concepto de estructura del Estado: "En un auténtico Estado de Bienestar por lo menos la mayoría de las actividades rutinarias de cada día deben estar dedicadas a atender las necesidades del bienestar social de sus hogares" (Esping - Andersen, 1993: 39). En el terreno económico, la acción fundamental fue el desarrollo del proteccionismo que van a aplicar a todos los Estados.

Otro enfoque conceptual para caracterizar los Estados de Bienestar es el propuesto por Titmus citado en la obra Esping-Andersen-, quien diferencia entre Estados de Bienestar "residuales" e "institucionales". "En los primeros el Estado solo asume la responsabilidad cuando ha fallado la familia y el mercado, procura hacerse cargo de los grupos sociales marginales o necesitados. El segundo modelo se dirige a toda la población, es universalista y abarca un compromiso institucionalizado de protección social" (Esping - Andersen, 1993: 40) señala el autor sueco.

\section{La Ciudadanía y la extensión de Derechos}

Las reivindicaciones sociales que cautelan los Estados de Bienestar y su implementación según el sistema político del gobierno de turno en Europa, se explican en las conferencias "Ciudadanía y Clase Social" del sociólogo Thomas Humphrey Marshall, pronunciadas en Cambridge en 1950 (Marshall, 1997: 302). En ellas, el autor analiza la génesis y repercusiones de las políticas sociales implementadas en la Europa de la post-guerra, a través del concepto de "ciudadanía" y los derechos civiles, sociales y políticos asociados a esta.

Estos tres tipos de derechos ciudadanos de carácter universal, que fueron establecidos de forma cronológicamente diferenciada en distintas etapas de la historia de los países europeos:

1. Derechos civiles: Agrupan al conjunto de libertades individuales (de palabra, de pensamiento, de culto). Se incluyen el derecho de propiedad, de establecer contratos y el acceso a la justicia. El siglo XVIII fue el periodo histórico en que emergió el proceso de afirmación de estos derechos, dando origen a diversas instituciones, como los tribunales de justicia.

2. Derechos políticos: Esta es la ampliación de los derechos civiles al derecho a voto sin limitación de clase (sufragio universal) y la posibilidad ocupar cargos públicos. Se expresan institucionalmente en los parlamentos, los gobiernos estaduales y locales, y los partidos políticos. Fue durante el siglo XIX donde se instauró de manera generalizada la extensión de los derechos políticos.

3. Derechos sociales: Este conjunto de derechos incluye desde el derecho a un mínimo de bienestar y seguridad económica, hasta el derecho a compartir plenamente el patrimonio social y a vivir como un ser civilizado, de acuerdo con los patrones vigentes en la sociedad. Las instituciones más estrechamente vinculadas con este tipo de derechos son el sistema educacional y los servicios sociales. El siglo XX fue el periodo por excelencia de extensión de estos derechos. Entre estos, Marshall incluye aquellos que tienen los trabajadores para ser protegidos de las enfermedades y accidentes del trabajo, a tener una vivienda y una jubilación, mutualidades de previsión, ayudas a vivienda, y políticas de pleno empleo. 


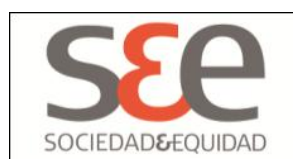

La "ciudadanía social" es una idea central de este modelo señalado por Marshall, en el que "los derechos sociales en su forma moderna suponen la invasión del contrato por el estatus, la subordinación del precio de mercado a la justicia social, la sustitución de la libre negociación por la declaración de derechos" (Marshall, 1997:335). Desde esta perspectiva, la ciudadanía ya no sólo se aborda desde los presupuestos de los derechos civiles y de los derechos políticos sino que, además, incluye la categoría de los "Derechos socioeconómicos" para todos los sujetos que componen la sociedad.

En este sentido Kymlicka y Norman legitiman la propuesta de Marshall en cuanto al rol que debe cumplir el Estado de Bienestar como ente cautelador de los derechos sociales del ciudadano: "para Marshall, la más plena expresión de la ciudadana requiere un Estado de Bienestar liberal/democrático. Al garantizar a todos los derechos civiles, políticos y sociales, este Estado asegura que cada integrante de la sociedad se sienta como un miembro pleno, capaz de participar y de disfrutar de la vida en común" (Kymlicka y Norman, 1997: 7).

De este modo, el concepto de ciudadanía redefine la relación Estado-sociedad y además permite establecer vínculos individuales entre sectores sociales y el Estado. Se exige el compromiso del sujeto de involucrase con la esfera pública y una serie de obligaciones expresada por ejemplo en la participación en los procesos de movilización impulsados por el Estado vinculados a la defensa nacional, en la tributación y el sufragio, rasgos que caracterizan las democracias inspiradas en principios liberales, pero ahora con intervención directa del Estado como facilitador de derechos ciudadanos.

\section{Formación Estado de Bienestar en Europa y Estados Unidos}

Un recorrido por el proceso histórico de formación y consolidación del Estado de Bienestar en Europa y Estados Unidos es útil para apreciar la transformación paulatina desde Estados liberales a Estado de Bienestar:

1. En el Reino Unido el paso de un Estado liberal a uno de Bienestar sucede a principios del siglo XX, con el desarrollo del Partido Laborista (Navarro et al, 2002: 7). En este periodo el movimiento obrero se convierte en una fuerza parlamentaria importante, ya que en 1908 se crea un sistema de pensiones para ancianos pobres seguida de un seguro de enfermedad y de paro de carácter obligatoria para determinados obreros. Durante la Segunda Guerra Mundial se presentan los informes Beveridge al Parlamento que darán lugar a la moderna concepción de la seguridad social.

2. Alemania es uno de los primeros países europeos en que un régimen autoritario se anticipa a las exigencias del movimiento obrero y adopta planes de seguridad social obligatoria antes de 1900. Los tres pilares de su política social, fueron las leyes implantadas por el Canciller Bismarck previamente mencionadas. En 1911 estas tres leyes se unifican y extienden en el código de seguros sociales. Estas reformas formaron la base del Estado de Bienestar que se extendió en Europa y que se mantiene con pequeñas modificaciones hasta hoy. 


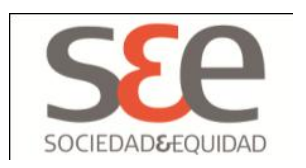

3. Suecia ha constituido el modelo de Estado y de sociedad de bienestar por excelencia, pero su desarrollo ha sido reciente, ya que se inicia cuando llegan los socialdemócratas al poder en 1932. Se sientan las bases para un compromiso estable entre trabajo y capital, el pleno empleo ha funcionado como una especie de religión estatal y se da un papel central a las políticas activas del mercado de trabajo. Las prestaciones de la seguridad social se definen en los años cincuenta como universales y obligatorias.

4. En Estados Unidos la introducción de políticas de seguridad social se producen tras la crisis de 1929. Se apoya el establecimiento de una legislación social y Roosevelt introduce su política del New Deal que se distingue en dos etapas. En la primera se adoptan medidas de asistencia social a desempleados y la intervención estatal en la economía para estimular la demanda. En la segunda etapa (1935) se fomentan dos pilares: la ley de seguridad social (pensiones privadas de vejez y desempleo) y la ley de relaciones de trabajo que reconoce los derechos de sindicación y negociación colectiva. Pero en Estados Unidos no se ha establecido nunca un sistema nacional de seguro médico universal, tema que fue tratado en el documental Sicko (2007) del director norteamericano Michael Moore y que también constituyó la gran novedad del programa del Presidente Barack Obama en cuanto a seguridad social propuesto para su actual gobierno.

En esta fase, las instituciones democráticas se hacen cargo de responsabilidades económicas y sociales de gran envergadura, lo que quizás sea la mayor transformación de su desarrollo institucional. El aspecto más significativo que asume el Estado se relaciona con la función "coordinadora" respecto del conjunto de la sociedad. Por medio de las políticas públicas y la planificación económica, coordina las acciones de los agentes económicos, el mercado laboral y los individuos para generar cohesión social.

Las herramientas características que utilizan estos nuevos Estados para entregar garantías sociales mínimas, son la intervención en la economía con el objetivo de lograr el pleno empleo y el desarrollo de las políticas de seguridad social. A este objetivo se añade la reducción de la desigualdad económica o la redistribución de la renta, instrumentalizada por medio del sistema impositivo y los gastos sociales.

Según Gómez, la fase de consolidación del Estado de Bienestar transcurre después de la Segunda Guerra Mundial“(...) así, tras 1945, las naciones que se reconstruyen y los vencedores son ya Estados reguladores e intervencionistas, sustentados en un pacto social, el cual, en la mayoría de los casos, cuenta con un reflejo constitucional, más o menos explícito" (Gómez, 1995: 263). Este periodo viene marcado por las experiencias previas del desempleo masivo de la crisis del 29, por las tensiones entre las clases sociales y por las experiencias de fascismo y comunismo en Europa. Ahora emergen las rivalidades imperialistas entre las grandes potencias (Estados Unidos, URSS, las dos Alemania y, Reino Unido) que paulatinamente se irán radicalizando hasta configurar el mundo bipolar de la guerra fría. Entra en crisis la misma economía de equilibrio liberal y se abre la idea de que la crisis sólo es superable mediante la intervención directa del Estado en la economía. 


\section{s\&e \\ SOCIEDADEEQUIDAD}

\section{El Consenso del Estado de Bienestar Keynesiano}

Tras la Segunda Guerra Mundial, el capitalismo se reconstruye de la mano de la democracia en forma consensuada. Pero, que para que se haya producido esta compatibilidad entre el capitalismo y la democracia, han tenido que surgir y desarrollarse dos principios mediadores: por una parte, los partidos políticos de masas y la competencia entre partidos y, por otra parte, el desarrollo de modelos económicos de corte keynesiano.

En este periodo, se da una adhesión a la democracia de la izquierda no comunista, encarnada por las tendencias socialdemócratas, las que se articulan en partidos de masas. Los partidos socialdemócratas fueron quienes inicialmente promueven la política social y la política de protección implementada por los distintos Estados de Bienestar. La conflictividad entre partidos se reduce siguiendo la forma de cooperación política que redunda en gobiernos de coalición nacional. Los partidos socialistas van a influir en la acomodación del movimiento obrero a los nuevos objetivos de la política gubernamental y el mismo sistema socioeconómico genera mecanismos para encauzar luchas de clases del proletariado de forma institucionalizada (corporativismo), legitimando el Estado social en un sistema económico capitalista.

Así el Estado de Bienestar Keynesiano se constituye en la forma característica del Estado en las economías capitalistas industriales, y se presenta y se legitima como una formulación de un nuevo contrato social. Como plantea Bobbio:

La revolución keynesiana, por fin, ha conducido a la liquidación de la política del laissez faire y al nacimiento de una nueva política económica basada esencialmente en la intervención sistemática del Estado, al que se asigna un papel económico central. A él concierne, en efecto, la tarea de ejercer una función directiva sobre la propensión al consumo a través del instrumento fiscal, la socialización de las inversiones y la política del pleno empleo. (Bobbio, 2002: 5)

De esta manera, con el papel que asume el Estado para garantizar el pleno empleo evitando las crisis cíclicas del capitalismo y redistribuyendo riqueza, se consigue la ecuación keynesiana: compaginar la justicia social con la acumulación de capital. Donde sea compatible el crecimiento económico, el reparto equitativo de los resultados de ese crecimiento, la acumulación de capital y la legitimación del sistema.

Desde el estructural funcionalismo, dominante durante los años 50 y 60 , se sostuvo que el consenso social que generaba el Estado de Bienestar contribuía a las distintas partes del sistema social. Por medio de la integración, coordinación y armonización de intereses, el Estado de Bienestar jugaba un papel importante en la generación de armonía y consenso social, y constituía uno de los fundamentos del orden en las sociedades post - industriales.

De acuerdo a Habermas, fue la utopía de la sociedad del trabajo y la liberación del trabajo asalariado, lo que inspiró a los movimientos obreros y que se adaptó a la forma de Estado de Bienestar. Este tipo de organización sería heredera de los movimientos burgueses de 


\section{s\&e \\ somenowo}

emancipación y del Estado democrático. Por medio de los mecanismos de la democracia el Estado buscaría apaciguar los antagonismos de clases y a la vez proteger el crecimiento natural capitalista.

\section{Análisis de los Estado de Bienestar Período Postguerra}

Durante los años posteriores a la Segunda Guerra Mundial, entre 1945 y 1950, el Estado de Bienestar se convirtió en una realidad institucionalizada en la mayor parte de los países capitalistas occidentales. La forma de institucionalización que se adopta para el Estado de Bienestar en cada país, viene marcada por las relaciones entre las fuerzas sociales en acción, por las fuerzas políticas que lideran el proceso y por las normas institucionales puestas en marcha antes y durante la guerra.

Gøsta Esping-Andersen propone distinguir tres regímenes del Estado de Bienestar a partir de las diferencias internacionales que encuentra en la calidad y condiciones de los derechos sociales, en la estratificación social del bienestar y en la relación existente entre el Estado, el mercado y la familia (Esping Andersen, 1993: 50).

1. Estado de Bienestar liberal: En este modelo predominan ayudas solo a los más pobres, las transferencias o seguros sociales son focalizados; el Estado estimula al mercado en el campo del bienestar. Los ejemplos son Estados Unidos, Canadá, Australia y Gran Bretaña que gastaba menos en la Seguridad Social que la gran mayoría de países europeos (Kohl, 1981). Las reglas para estos derechos son estrictas y a menudo está asociadas a un estigma (indigencia, grupos étnicos, cesantía, sectores vulnerables).

2- Estado de Bienestar conservador/corporativista: En estos modelos de bienestar predomina la conservación de las diferencias de status; por lo que los derechos están vinculados a la clase social. Este modelo fue implementado en países como Alemania, Austria, Francia o Italia. Este corporativismo fue subsumido bajo una estructura estatal perfectamente preparada para desplazar al mercado como proveedor de bienestar social; de ahí que los seguros particulares y los beneficios adicionales en el empleo jugaran un papel marginal. Estos Estados están fuertemente involucrados con la iglesia y por eso el interés por conservar la familia tradicional. La seguridad social suele excluir a las mujeres que no trabajan y los subsidios familiares estimulan la maternidad. Los centros de día y otros servicios de ayuda familiar similares están claramente subdesarrollados; el principio de la "subsidiaridad" sirve para destacar que el Estado intervendrá solamente cuando se acabe la capacidad de la familia para atender a sus miembros.

2. Estado de Bienestar socialdemócrata: En este Estado de Bienestar, el principio de universalización y de desmercantilización de los derechos sociales se han extendido también a las nuevas clases medias; la política de emancipación se dirige tanto al mercado como a la familia tradicional. En este régimen es necesario que se produzca una fusión entre bienestar social y pleno empleo. Suecia y los demás países nórdicos serían los ejemplos de regímenes socialdemócratas. Más que aceptar el dualismo entre Estado y mercado y entre la clase obrera y las nuevas clases medias, buscan un Estado de Bienestar que promoviera una igualdad en los estándares más elevados, no una igualdad en las necesidades mínimas. 


\section{s\&e \\ SOCIEDADEEQUIDAD}

\section{Problemas y crisis del Estado de Bienestar}

Si bien en el análisis de los Estados de Bienestar modernos que presenta Esping-Andersen, se puede apreciar el efecto redistributivo de carácter igualador, que los Estados de Bienestar generan en la estratificación social y el mercado de trabajo, su viabilidad financiera, legitimidad social transversal y permanencia en el tiempo se verían amenazadas.

El crecimiento económico sostenido y el pleno empleo que se había logrado en la mayor parte de los países occidentales desde los años cincuenta, a partir de los años setenta empiezan a disminuir de forma repentina. Con esto comienza un proceso de desbaratamiento del modelo de desarrollo del Estado de Bienestar Keynesiano. Paralelamente, aumentan los requerimientos de prestaciones hacia el Estado y disminuyen los cotizantes al sistema de seguridad social. La crisis se verá agudizada por la subida del precio del petróleo que produce una contracción económica en gran parte de los países de Europa.

Como efecto contracíclico se genera una absorción de la mano de obra en la actividad industrial lo que redunda en una sobreproducción que previamente se paliaba con comercio internacional. La crisis internacional impide eso y agudiza la sobreproducción. Se empieza a producir una crisis significativa que se manifiesta en distintas esferas:

1. El trabajo a tiempo indefinido es reemplazado por la flexibilidad laboral.

2. Se modifican las relaciones contractuales en el empleo público.

3. Traspaso de actividades públicas al sector privado.

4. Los gastos del Estado tienden a incrementarse más rápidamente que los medios para financiarlos.

Surgen múltiples críticas, principalmente de sectores de la nueva derecha neoliberal, que proponen desmantelar las instituciones de protección social implementadas por el Estado de Bienestar, disminuir el gasto público, bajar los impuestos y retomar un camino hacia un desarrollo de la economía autorregulada.

El Estado de Bienestar se ha convertido en una matriz que estructura la sociedad; define sus contornos y ha acercado a las clases sociales, hacia una universalización del status de clase media. Este hecho ha sido explicado por Minc, quien plantea que: "durante diez años, los sociólogos de todo tipo han venido profetizando la irrupción de las clases medias y con ellas de la igualdad. Daban por sentada la eficacia de la máquina igualitaria ignorando sus disfunciones y sus límites. La clase media existe, pero más allá de las apariencias de identidad, ¿encarna la igualdad?" (Minc, 1989:75). Como el mismo Esping-Andersen advierte, las mismas políticas de redistribución de la riqueza presentarían problemas de legitimidad en las esferas sociales menos vulnerables ya que "finalmente, cualquier programa para igualar drásticamente los ingresos choca, sin duda, con gran hostilidad entre la clientela de la clase media. Por estas razones, resultaría que el crecimiento de las nuevas clases medias abortaría el proyecto socialdemócrata y reforzaría una forma liberal de Estado de Bienestar" (Esping- Andersen, 1993: 53)

El problema se agudiza aún más en los Estados de Bienestar de carácter universalista, en los que nadie -ni siquiera los sectores más pudientes- es excluido. La extensión de los derechos sociales de los ciudadanos a "derechos socioeconómicos" para todos los sujetos que componen la sociedad y que materializan en la categoría universal de "ciudadanía social" mantiene y reproduce 


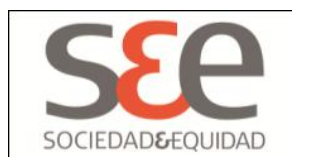

la desigualdad pues las clases medias se benefician del Estado de Bienestar, tanto o más que los menos aventajados.

El ataque de la derecha consiste en señalar que la crisis económica es consecuencia de una mala gestión fiscal, de un exceso de recursos que concentra el Estado y de ser un obstáculo para la libre economía. Estos cuestionamientos provienen de los sectores neoliberales, encabezados por Hayek y Friedman. Según estos autores, la competitividad en el mercado sería, el mejor, o el menos malo, de los posibles modos de regulación. Según Hayek, el mercado es "el sistema que permite asegurar de la mejor manera posible la movilización de las informaciones, conocimientos y competencias necesarias para la regulación del sistema social." (Hayek, 1960: 22).

Esta ideología desaprueba ciertas tendencias del Estado del bienestar, ante todo la "cruzada" por la igualdad social. La igualdad material y la libertad serían antitéticas y, como Friedman ha declarado "no se puede ser al mismo tiempo un igualitario y un liberal" (Friedman, 1966: 195). En el centro de la argumentación neoliberal está la idea de que en el Estado moderno coexisten en realidad dos Estados: un Estado de Derecho, guardián de la democracia y garante de las libertades esenciales, y un Estado intervencionista que destruye esas libertades. Sería necesario, en consecuencia, reducir o suprimir el segundo para conservar el primero.

Surge además otro diagnostico crítico desarrollado por la izquierda socialista. Estos sectores plantean que la estructura institucional del Estado de Bienestar no permite alterar la distribución del ingreso entre las clases sociales. La organización del trabajo y los sistemas de seguridad social no eliminarían las causas que producen las situaciones de inseguridad, sino que más bien se concentran en los resultados. Concretamente no eliminan las causas de los accidentes laborales, el desempleo, o la organización del mundo urbano, sino que tiende a generar compensaciones por las consecuencias de esos eventos. Los Estados de Bienestar lo que harían es encubrir por medio de la seguridad social las desigualdades sociales, no terminando con ellas, sino legitimándolas en el sistema.

Para los sectores de izquierda más dura, el Estado de Bienestar ejercía un notorio control político e ideológico legitimador del capitalismo y de la moral burguesa, que promueve concepciones que generan efectos negativos en la lucha social y la conciencia de clase. Desde la Escuela de Frankfurt, Herbert Marcuse plantea que producto de la hegemonía de la racionalidad tecnológica, instrumentalizada como sistema de dominio, en el Estado de Bienestar el individuo ha sido anulado por la sociedad, del mismo modo que se imposibilita un cambio cualitativo que origine nuevas formas de existencia más humanas. La configuración de la "unidimensionalidad" del sujeto en las sociedades modernas es un proceso que se desarrolla en todos los planos de la vida social.

De este proceso propio de las sociedades del capitalismo avanzado Marcuse evidencia dos nuevos aspectos de dominación, control y represión social:

[...] la asimilación de las fuerzas y de los intereses de oposición en un sistema al que se oponían en las etapas anteriores del capitalismo, y la administración y la movilización metódicas de los instintos humanos, lo que hace así socialmente manejables y utilizables a elementos explosivos y «antisociales» del inconsciente. (Marcuse, 1985: 7) 


\section{sfe \\ somenowo}

Para Marcuse la sociedad capitalista actual es capaz de asimilar cualquier forma de oposición que surja al interior de sí misma, y por tanto no existe ningún movimiento individual ni colectivo capaz de oponérsele o de socavar sus raíces socioeconómicas. El sistema capitalista ha generado a través de los Estados de Bienestar una intervención que mejora el nivel de vida de los obreros, pero eso no cambiaría su condición de explotados.

Además, de acuerdo a esta crítica, el Estado de Bienestar difunde una imagen falsa de dos esferas que se muestran absolutamente disociadas. Por un lado la esfera económica y productiva dependiente de la acción de los planificadores y técnicos y la esfera de la ciudadanía y del sistema político. Por ende el concepto de seguridad social tiende simplemente a hacer hincapié en los derechos sociales de ciudadanía y no en los derechos de los trabajadores de participar en la gestión económica o la gestión productiva.

\section{Vigencia y funcionamiento del Estado de Bienestar en la actualidad}

El fenómeno de la globalización ha significado una redefinición de los roles y el alcance de los Estados por lo que resulta pertinente preguntarse por los elementos propios del Estado de Bienestar que persisten en la actualidad, y si es que es posible y viable, dadas las actuales condiciones económicas internacionales, repensar nuevas formas de Estados benefactores.

Desde inicios de los 80 hasta la actualidad, hubo un cambio en el consenso en torno al rol del Estado en las políticas económicas en los países capitalistas, pasando de un modelo keynesiano de Estado de bienestar hacia un capitalismo post industrial estructurado por políticas neoliberales.

Este cambio de orientación se ha visto acentuado por el fenómeno de la actual globalización que básicamente consiste en un fenómeno de "penetración o interpenetración de mercados, especialmente de tipo financiero por un lado y de comunicación e información, por otro, que atraviesan las sociedades estatal-nacionales" (Garretón, 2007:19).

Esta nueva realidad determina fuertemente la capacidad de control que pueda establecer el Estado frente a la economía. Tal como afirma Castells, "no hay, hoy por hoy, control o regulación de los flujos globales de capital (salvo de forma limitada o coyuntural), lo que convierte a todas las economías en dependientes del comportamiento de los valores de sus empresas, acciones y obligaciones en los mercados financieros" (Castells, 2005:16). De acuerdo al autor esta pérdida de regulación estatal, se ve acentuada además por:

[...] la creciente importancia del comercio internacional en el crecimiento económico, el aumento considerable de la inversión extranjera directa, la globalización de una parte de la producción de bienes y servicios en torno a empresas multinacionales y a sus redes auxiliares, la interpenetración internacional de mercados de bienes y servicios, la formación de un mercado global de trabajadores de especial cualificación y la importancia dentro de la migraciones internacionales de mano de obra desplazada por las crisis económicas hacia zonas con mayores oportunidades de empleo y progreso. (Castells, 2005:17) 


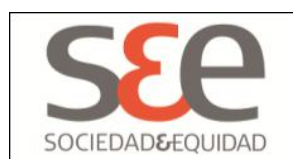

De este modo, la globalización vació a los estados de poder de decisión sobre el destino de los países y el tipo de desarrollo que desean tener. En ese sentido

[...] la globalización operó una verdadera transferencia de poder de decisión sobre los rumbos del desarrollo político y económico desde los países hacia instancias multilaterales ajenas, distantes y nada democráticas como el FMI, BM y OMC, cuando no directamente hacia los que reparten las cartas a nivel de mercado: los grandes conglomerados económico - financieros. (Grzybowski, 2004: 51)

A partir de $1989^{1}$, el modelo de desarrollo económico predominante y hegemónico a nivel mundial es el neoliberalismo. El neoliberalismo fue asumido como una ideología absolutamente opuesta a las antiguas concepciones keynesianas, o en el caso de América Latina a las posturas desarrollistas. Este modelo económico conjuga elementos como la innovación empresarial, inversión privada (nacional y extranjera) e incorporación de tecnologías en los procesos productivos, dando forma a una matriz socio-económica donde el Estado asume un rol de mero coordinador y facilitador entre los agentes económicos y la sociedad, dejando al mercado como el principal agente de producción y distribución de la riqueza, así como también se le asigna a los privados el papel de principal proveedor de bienes y motor del mercado laboral.

El neoliberalismo impuso su pensamiento único en la globalización económica, e incluso en el mundo académico. Surgen tesis neoconservadoras como "El fin de la historia" de Fukuyama (1994) que significaba el triunfo ideológico del liberalismo económico por sobre el pensamiento socialista, apuntalando el mercado como un mecanismo efectivo de regulación que fomenta una cultura global de consumo y en la democracia liberal como la única forma de organización política capaz de equilibrar las aspiraciones individuales y colectivas de libertad con el poder del Estado.

También se levantan posturas posmodernas, como la de Lipovetsky (2003) que profetizaba que las sociedades de fines del siglo XX y comienzos del XXI entraban en "La era del vacío" donde se enfatiza los comportamientos individualistas o narcisistas, que determinan un esquema simplista de costo-beneficio, reemplazando la categoría de "logro", que entraña necesariamente perseverancia y dedicación, por la de "triunfo rápido" y donde el Estado, como propuesta colectiva de desarrollo, tiene un papel residual y está totalmente jibarizado por el mercado y el consumo irreflexivo.

Bajo este escenario resulta complejo pensar un retorno del Estado como principal agente productivo y generador de bienes y servicios, que sustente políticas universalistas y que garantice los derechos civiles sociales y políticos que proponía Marshall. Sin embargo, las políticas impulsadas por el consenso de Washington -enmarcadas en una tendencia liberal en la cual se recomienda a los Estados dejar al mercado actual libremente en el marco de reglas de libre competencia- se han visto fuertemente cuestionadas durante los últimos años, entre otras cosas

\footnotetext{
${ }^{1}$ El Muro de Berlín cayó en la noche del jueves 9 de noviembre de 1989. Este evento marco el fracaso simbólico de los "socialismos reales" en Europa y el triunfo de la economía capitalista de corte neoliberal encabezada difundida al resto del mundo por EEUU.
} 


\section{SEe}

por su incapacidad de superar la pobreza, la exclusión y por aumentar la desigualdad social. Esto ha impulsado en muchos casos el retorno del Estado como agente interventor, para paliar la exclusión generada por el neoliberalismo y fomentar la cohesión social.

Un claro ejemplo de esta tendencia que le da un impulso al Estado en la esfera global ha sido la crisis económica mundial 2008-2010, en que debido a una grave crisis crediticia e hipotecaria, el gobierno estadounidense tuvo que inyectar 700 mil millones de dólares a la banca privada. Esta situación puso de manifiesto que los Estados siguen siendo los garantes del funcionamiento de la economía de mercado, y que por tanto, a diferencia de lo planteado por las corrientes neoliberales, hasta hoy cumple un rol fundamental en la economía global.

Se puede ver entonces que en el escenario actual si bien se han manifestado algunos elementos que dan cuenta de que el Estado aún actúa como una de las más importantes estructuras sociales y de las que goza de mayor confiabilidad, también coexiste con una clara propensión de los Estados a debilitarse ante los cambios que han traído aparejada la globalización y que muchas de las características que lo inscriben dentro de la categoría de "de Bienestar" han sido desmanteladas con las privatizaciones, externalización de servicios y subcontrataciones de empresas y servicios que antes otorgaban los Estados y que ahora deben costear todos, o gran parte, de los ciudadanos.

Es de esperar, que pese a las dificultades que actualmente tienen los Estados para ejercer un control efectivo sobre las actividades económicas en los países, y la hegemonía neoliberal en el sistema mundial, las sociedades sean capaces de resguardar los derechos los derechos políticos y sociales que se promovieron en los tiempos del Estado de Bienestar. Es importante que se reconozca en este tipo de Estados, más allá de su éxito o su fracaso, una instancia que permitió mejorar la calidad de vida de muchas personas y otorgar participación política a sectores excluidos, así como avanzar hacia una modernización más igualitaria. Las nociones de derechos sociales, civiles y políticos, que se instalaron en este período, no sólo forman parte de un itinerario de Estados Benefactores, sino que son imprescindibles para el desarrollo y funcionamiento de todos los sistemas que se consideran democráticos. 


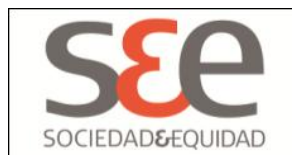

\section{Referencias}

Aracil, R.; Oliver, J.; Segura, A. (1998) El mundo actual: de la Segunda Guerra Mundial a nuestros días. Barcelona: Edicions Univers.

Bilbao, A. (1990). La lógica del Estado de bienestar y la lógica de su crítica: Keynes y Misses, en Papers, N 34, Universitat Autonoma de Barcelona.

Bobbio, N; Matucci, N y Pasquino, G. (2002) Diccionario de Política. Ciudad de México: Siglo Veintiuno.

Castells, M. (2005) Globalización, desarrollo y democracia: Chile en el contexto mundial. Santiago. Fondo de Cultura Económica.

Habermas, J. 1994. Ensayos Políticos. Barcelona: Editorial Península.

Esping-Andersen, G. (1993). Los Tres mundos del Estado de Bienestar. Valencia: Ediciones Alfons El Magnanim.

Fukuyama, F. (1994) El fin de la historia y el último hombre. Barcelona: Planeta-Agostini.

Friedman, M. (1966). Capitalismo y libertad. Madrid: Ediciones Rialp S. A.

(1960) Los fundamentos de la libertad. Madrid: Unión Editorial.

Garretón, M. A. (2007) Del Post-Pinochetismo a la Sociedad Democrática. Globalización y Política en el Bicentenario. Santiago: Debate.

Grzybowski, C. (2004). La democracia en América Latina, contribuciones para el debate. PNUD.

Gómez, J. M. (1995). El Estado del Bienestar y el reto de la solidaridad. Anales de Estudios Económicos y Empresariales. Número 10.

Hayek, F. (1960) Los fundamentos de la libertad. Madrid: Unión Editorial.

Hobbes T. (1980) Leviatán, México: Fondo de Cultura Económica.

Hobsbawm, E. (1998). Historia del siglo XX. Buenos Aires: Crítica.

Kymlicka, W y Norman, W. (1997): El retorno del ciudadano. Una revisión de la producción reciente en teoría de la ciudadanía. Revista Ágora, № 7, invierno de 1997. pp 5-42.

Lipovetsky, G. (2003) La era del vacío: Ensayos sobre el individualismo contemporáneo. Barcelona: Anagrama.

Marcuse, H. (1985) El hombre unidimensional. Barcelona: Planeta.

Marshall, T. H. (1997) Ciudadanía y clase social. Revista Española de Investigaciones Sociológicas (REIS). $N^{\circ}$ 79. Centro de Investigaciones Sociológicas. pp $297-344$.

Minc, A. (1989) La Máquina igualitaria: crisis en la sociedad del bienestar. Editorial Planeta. 


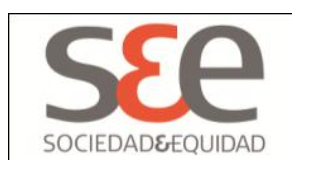

Mishra, R. (1989) El Estado del Bienestar después de la crisis: los años ochenta y más allá. En Muñoz de Bustillo, R. Crisis y futuro del Estado del Bienestar. Madrid: Alianza.

Navarro, V; Schmitt, J; Astudillo, J. (2002): La importancia de la política en la supuesta globalización económica. La evolución de los estados del bienestar en el capitalismo desarrollado durante la década de los años noventa. Sistema 171: 3-46.

Offe, C. (1990) La política social y la teoría del Estado. En Contradicciones en el Estado del Bienestar. Madrid: Alianza Editorial.

Polanyi, K. (1989) La gran transformación. España: La Piqueta.

Smith, A. (2000) Ensayo sobre la naturaleza y las causas de la riqueza de las naciones, México: Fondo de Cultura Económica.

Van Parijs, P. (1995), Más Allá de la Solidaridad. Los Fundamentos Éticos del Estado de Bienestar y de su Superación En: Alonso, M. A. y Giraldo Ramírez, J. Ciudadanía y derechos humanos sociales. Medellín: ENS. 
Rev. Sociedad\&Equidad № 1, Enero de 2011. Pp. 1-8

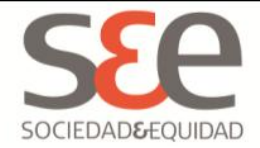

